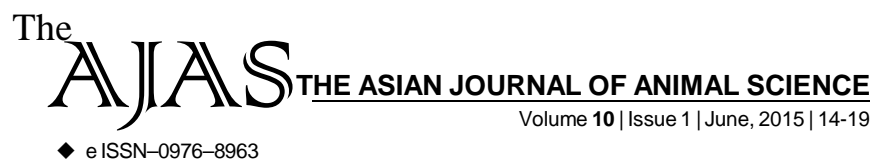

DOI : 10.15740/HAS/TAJAS/10.1/14-19 Visit us | www.researchjournal.co.in $\mathbf{S}$

\title{
Seasonal study of physico-chemical parameters of Kalisarar dam reservoir of Gondia district
}

DHARNA R. TEMBHARE

AUTHOR FOR CORRESPONDING :

\section{DHARNA. R. TEMBHARE}

Dhote Bandhu Science College, GONDIA (M.S.) INDIA

Email: dharna.bisen@gmail.com
ABSTRACT...... The precipitation which is the main source of water gets contaminated as soon as it reaches on the earth's surface. During its flow anthropogenic activities in the surrounding area add further impurities in it. Flow of rivers become impeded and are regulated due to construction of dam. This brings about changes in abiotic and biotic factors compared to untamed rivers. The response of each river to dam differs. The present study was aimed to analyze the physico-chemical parameters of the Kalisarar dam reservoir carried out from the month of June 2012-May 2013. The sampling stations were divided by a measurable distance and samples were collected every month. The parameters such as temperature, $\mathrm{pH}$, conductivity, dissolved oxygen, free carbon dioxide and turbidity were analysed. The paper highlights the condition of the reservoir in various seasons with respect to parameters mentioned above.

KEY WORDS...... Precipitation, Anthropogenic, Contaminated, Untamed

HOW TO CITE THIS ARTICLE - Tembhare, Dharna R. (2015). Seasonal study of physico-chemical parameters of Kalisarar dam reservoir of Gondia district. Asian J. Animal Sci., 10(1) : 14-19.

ARTICLE CHRONICLE - Received : 19.02.2015; Revised : 08.04.2015; Accepted : 22.04.2015 